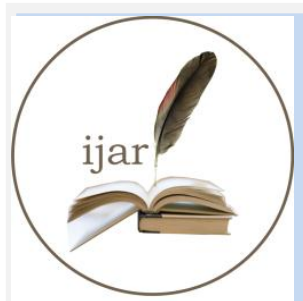

ISSN NO. 2320-5407
Journal Homepage: -www.journalijar.com INTERNATIONAL JOURNAL OF ADVANCED RESEARCH (IJAR)

Article DOI: 10.21474/IJAR01/9029

DOI URL: http://dx.doi.org/10.21474/IJAR01/9029

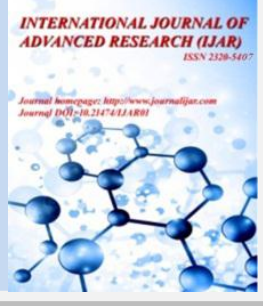

RESEARCH ARTICLE

\title{
AWARENESS OF BLEEDING DISORDERS AND ANTI-COAGULANT TREATMENT IN PATIENTS- A SURVEY OF DENTISTS IN THREE DISTRICTS OF KERALA.
}

\author{
Dr Jithin $\mathbf{P}^{1}$,Dr Anuradha Sunil2, Dr Archana Mukunda2, Dr Meera $\mathbf{P}^{3}$, Dr Arun Mohan ${ }^{3}$ and Dr Neethu \\ Kader ${ }^{3}$. \\ 1. PG student,Dept of Oral \& Maxillofacial Pathology,Royal Dental College, Chalissery, Kerala. \\ 2. Professor, Dept of Oral \& Maxillofacial Pathology Royal Dental College Chalissery, Kerala. \\ 3. Reader,Dept of Oral \& Maxillofacial Pathology, Royal Dental College, Chalissery, Kerala.
}

\section{Manuscript Info}

\section{Manuscript History}

Received: 08 March 2019

Final Accepted: 10 April 2019

Published: May 2019

Key words:-

Awareness; Bleeding disorders;

Coagulation tests; Anticoagulants.

\begin{abstract}
Background:Dentists treat their patients with both surgical and nonsurgical approaches in day to day practice. Most oral lesions are treated by non-surgical approaches whereas a few of them require definite surgical approach. Surgical dental procedures inevitably result in bleeding. Achieving hemostasis can be a challenging task. This study was schemed to measure the knowledge of dentists regarding bleeding disorders, coagulation tests and anticoagulants used in their patients. Materials and Methods:In this descriptive-analytical study, a questionnaire (consist 22 questions) was designed with the help of specialists in the field of oral pathology, oral medicine, physician and hematology. This questionnaire was distributed among 200 general practitioners. Collected information was analyzed with SPSS version 16.

Results:The mean mark for dentist's knowledge regarding bleeding disorders was $9.40 \pm 1.30$ (categorized moderate level). There was no significant difference in the mean knowledge scores among male and female dentists. Tukey's test displayed a significant difference in the mean knowledge level among 21 to 30 years old and over 45 years old dentists $(\mathrm{p}<0.03)$.

Conclusion:The present research indicated that dentists' awareness of bleeding disorders is not at optimal level. So it is necessary to hold codified/check listed instructional programs and to provide the needed knowledge in this respect to dental students as well as to the dentists currently working.
\end{abstract}

Copy Right, IJAR, 2019,. All rights reserved.

\section{Introduction:-}

The treatment plan in dental practice comprises of both non surgical and surgical techniques in day to day practice. Usually most of the oral lesions are treated by non surgical approaches few of them require definitive surgical approach which is inevitably associated with bleeding. Achieving homeostasis can be a challenging task and is further complicated in patients with systemic diseases or bleeding disorders. Bleeding disorders are conditions in

Corresponding Author:-Dr Archana Mukunda.

Address:-Professor, Dept of Oral \& Maxillofacial Pathology Royal Dental College Chalissery, 
which ability of blood vessels, platelets, and coagulation agents to establish hemostasis is altered. ${ }^{1}$ It is of 2 types namely Acquired or Inherited. Acquired coagulation disorders are caused by intake of certain medicines and special systemic diseases. ${ }^{2}$ Inherited bleeding disorders (IBDs) are caused by quantitative and qualitative alterations of either platelets or plasma proteins involved in coagulation and fibrinolysis. Hemophilia A, hemophilia B (Christmas disease) and von Willebrand's disease are the commonly encountered congenital coagulation defects. Von Willebrand disease is the most common inherited coagulation disorder which results from deficiency of Von Willebrand factor and involves nearly $1 \%$ of total population. ${ }^{2}$

Most reported bleeding episodes are minor and do not require a visit to the dentist or the emergency department and do not affect dental treatment significantly. However in case of severe bleeding disorder even a minor surgical procedure can result in uncontrolled bleeding and even death of the patient. ${ }^{3}$ General dental practioners (GDP) should be aware of systemic disorders and treatments that may cause complications in the dental setting.

As there are only limited studies regarding the awareness of dentists about bleeding disorders, coagulation tests and anticoagulant therapy we are conducting this study to assess the scenario among dentists in three districts of Kerala.

\section{Aim}

To assess the knowledge of dentists regarding bleeding disorders and common anticoagulants used in patients.

\section{Objective}

To understand the awareness among dentists regarding bleeding disorders, coagulation tests, action and risks of common anticoagulants on their patients.

\section{Materials and Methods:-}

Taking into account significance of bleeding in a variety of dental procedures and necessity of dentists' familiarity with common bleeding disorders, anticoagulants used and coagulation tests, a close ended questionnaire was prepared. The study was descriptive-analytical to assess the awareness among dentists. The questionnaire was designed with the help of oral pathologist, oral medicine specialist, a physician and a heamatologist. The questionnaire consisted of total 22 questions divided into two sections (personal specifications and awareness). The emphasis in the questionnaire was on bleeding disorders, screening tests and anticoagulants. The dentists participating in this survey were randomly selected and questionnaires distributed among them and responses were personally collected on the same day. The unwilling dentists and those who are not active in practice were excluded from the current study.

Out of 200 dentists, 178 dentists filled the aforementioned questionnaire. The variables used for the statistical analysis are Age and post-graduate duration. Age variable was divided into 3 categories: below 30 years, 31 to 40 years, and over 40 years. Variable of post-graduation duration was also classified into 4 categories: below 5 years, 510 years, 10-15 years, and more than 15 years. Responses in each fields of questionnaire were taken into account. A positive point was given for every correct answer and a zero score was assigned to every incorrect (false or blank). The numerical values were entered on an excel sheet and was statistically analyzed. Finally, the total sum of awareness score for dentists was assumed to be 22. The values obtained were converted to cumulative percentage. For ranked evaluation of awareness level, sum of dentists' scores acquired from responding to the questions were used. Thus, awareness was categorized into three levels: poor (0 to 8), moderate (9-16), and good (17-22).

\section{Results:-}

Response percentage of dentists to questionnaires was $89 \%$ out of which $62 \%$ were graduates and $38 \%$ were postgraduates. $62.2 \%$ of participating dentists were male and the $37.8 \%$ were female. Average age of dentists was $34.3 \pm 5.9$ years (with variation range of 25 to 69years) (Table 1 ). Around $62.5 \%$ of the practioners had $<5 y r s$ of clinical practice; $23.4 \%$ had 5-10yrs of clinical practice and only $14.1 \%$ had clinical practice of $>10 y$ rs.

$90 \%$ of the dental practioners claimed that they record complete medical history of patients visiting them and $78.9 \%$ emphasized on bleeding disorders and anticoagulant therapy. The practioners screened the bleeding disorders with clotting time $50 \%$, bleeding time $51.6 \%$, whereas only $1.6 \%$ advised none of the tests to screen bleeding disorders. Aspirin was identified as the common drug prescribed for bleeding disorders by $92.2 \%$ and hemostat factor IX was the least recognized drug. $52.3 \%$ of the practioners believed that anticoagulants should be stopped 5-7days prior to any invasive procedure whereas $2.4 \%$ of them felt that discontinuation of anticoagulants is not required. $77.3 \%$ of 
practioners thought anticoagulants must be restarted in less than 5 days post surgical procedure whereas $4 \%$ felt that it was not applicable. $80 \%$ of the practioners admitted that they refer the patients to a physician or a hematologist whenever required with $20 \%$ of the practioners admitting they do prescribe and alter the dose of anticoagulants on their own. All the practioners unanimously $100 \%$ accepted that they take special precaution while treating patients with myocardial infarction $82 \%$ while treating patients with cirrhosis and $93 \%$ while dealing with patients on dialysis. Special emphasis was given to patients with leukemia in $95.3 \%$ and $90.6 \%$ with transplant. $30 \%$ of practioners excise special emphasis on sterilization while treating high risk patients. $70 \%$ of the dental practioners accepted that they modify the antibiotics for such patients. Only $12.5 \%$ of practioners are equipped to screen bleeding disorders in their clinical setup. $40 \%$ of the practioners accepted that they were reluctant to perform surgical procedure when a bleeding or clotting disorder was suspected. $74.6 \%$ responded affirmatively that they would refer patients with bleeding disorders to either a physician or a hematologist whereas the rest $25.4 \%$ stated that they would perform no dental procedure in these cases.

\begin{tabular}{|l|l|l|l|}
\hline Age \pm Standard deviation & Percentage & \multicolumn{2}{|l|}{} \\
\cline { 1 - 3 } $34.3 \pm 5.9$ years & Age (years) & \multirow{2}{*}{ Gender } \\
\hline & $62.2 \%$ & Male & Responsibility to \\
& $37.8 \%$ & questionnaire & Awareness Level \\
\hline & $89 \%$ & Response & \\
\hline & $11 \%$ & No Response & \\
\hline & $51.3 \%$ & Moderate & \\
\hline & $36.8 \%$ & Poor & Good \\
\hline & $11.9 \%$ & to &
\end{tabular}

Table 1:-percentage and frequency of gender, Responsibility to questionnaires and awareness level

\section{Discussion:-}

Uncontrolled bleeding can be a dangerous complication in any clinical setup. This may further be worsened if there is an underlying systemic disorder. However awareness about bleeding disorders and anticoagulants will provide a positive approach in handling such patients. ${ }^{4,5}$

Our study was an attempt to assess the awareness of dental practioners about bleeding disorders. We found in our study that there as good awareness among GDP to record a detailed medical history with special emphasis on bleeding disorders. This detailed information may give a clue the severity of the underlying bleeding coagulopathy which will be helpful in taking necessary measures to treat the patients. When coagulapathies are associated with systemic conditions it may necessitate consulting a physician. ${ }^{6}$

We noted that most of them are familiar with screening tests like clotting time, bleeding time, prothrombin time etc but less familiar with partial thromboplastin time. Majority of GDP relied on values of bleeding test (BT) as a screening test for underlying bleeding disorders. Interestingly only a small population did perform this test in their own clinical setup. We also noted that partial thromboplastin time (PTT) was the least advised as it has less specificity than other tests. The anticoagulant activity level based only on PT is difficult when thromoboplastic agent is added to plasma as discrepancy in thromboplastic activity may alter PT values. Such discrepancies can be minimized using International Normalized Ratio INR to assess PT value. Awareness of INR among general dentist has been low as per studies of Robati R. ${ }^{7}$

Majority of the Dentists felt that anticoagulants need to be stopped 5-7 days prior to the surgery and re-instituted less than 5 days after surgery. Contrary to the earlier belief that warfarin needs to stopped during dental procedure is no longer valid. The anticoagulation guidelines suggest that warfarin can be continued during most of the dental treatments. Such unwarranted discontinuation of drugs may results in increased risk of thromoembolic complications. ${ }^{8}$

In our study Aspirin was identified as the most common anticoagulant which needs to be discontinued atleast 3 days before the surgical procedure which correlates the previous study by Robati $\mathrm{R}$ in $2013.7,9,10$ 
We were amazed to find that a small population of dentists felt that they can prescribe or alter the dose of anticogulants. These dentists must be advised to take an opinion from the physician rather than directly prescribe to the patient. Alteration of dose of drugs may also lead to the above mentioned complication. ${ }^{3}$

Majority of GDP did employ necessary precautions while treating patients with a previous history of myocardial infarction, cirrhosis, leukemia, dialysis patients with chronic renal failure. We emphasize that drug doses need to be frequently modified in patients with this condition after consulting the physician. In spite of the awareness that people with systemic diseases need precautions while treatment, very few gave importance to sterilization procedures while handling such patients. The direct and indirect complications of lack of proper sterilizations should be emphasized.

Though the dentists were aware about bleeding disorders majority of them were hesitant to treat such patients. This can be rectified by instituting a positive approach along with interdisciplinary approach. The common post operative complications in patient with bleeding disorders are hemorrhage and hematoma. It is noted that complications arise even with nerve block especially inferior nerve block which may lead to airway obstruction. Such a complication can be minimized by using Gow Gates technique. ${ }^{11}$ We therefore believe practioners with sound knowledge about bleeding disorders would offer best prophylactic, restorative and surgical treatments to patients with bleeding disorders.

\section{Conclusion:-}

It is imperative for dentists to have knowledge of bleeding disorders and anticoagulant therapy and the risks associated with them. The present research indicated that dentists' awareness of bleeding disorders is not at a desirable level. It is necessary to hold codified/check listed instructional programs and to provide the needed knowledge in this respect to dental students as well as to the dentists currently working. Planning for continuing education courses in colleges and after graduation as well as for practicing dentists to update current levels of knowledge and distribution of educative handouts with stepwise instructions on handling of patients with bleeding disorders is recommended.

\section{Conflict of Interest}

The authors have no conflict of interest.

\section{Reference:-}

1. Little J, Falace D, Miller C. Dental management of the medically compromised patient. 7th ed. St Louis: Mosby Elsevier; 2008. P. 396-432.

2. Greenberg M, Glick M, Ship J. Burkets9s Oral Medicine. 11th ed. Hamilton, Canada: Bc Decker Inc; 2008. P. 412-34.

3. Anurag Gupta, Joel B. Epstein, Robert J. Cabay. Bleeding Disorders of Importance in Dental Care and Related Patient Management. JCDA 2007;73:77-83.

4. Aframian DJ, Lalla RV, Peterson DE. Management of dental patients taking common hemostsis-altering medications. Oral Surg Oral Med Oral Pathol Oral Radiol Endod. 2007; 103: 1-11.

5. Salehi MR. Evaluation the knowledge and application of Isfahan dentists about coagulation tests in patients with coagulation disorders. Journal of Isfahan Dental School. 2006; 2: 59-62.

6. Lockhart PB, Gibson J, Pond SH, Leitch J. Dental management considerations for the patient with an acquired coagulopathy. Part 1: Coagulopathies from systemic disease. Brit Dent J. 2003; 195: 439-45.

7. Robati R, Farokhi MM. Evaluation the dentists' awareness of inherited bleeding disorders and anticoagulants in Shiraz. Iranian Journal of Pediatric Hematology Oncology 2013;3:159-163.

8. Linnebur SA, Ellis SL, Astroth JD. Educational practices regarding anticoagulation and dental procedures in U.S dental schools. J Dent Educ. 2007; 71: 296-303.

9. Weksler BB, Moore A, Tepler J. Hematology: Cecil's essentials of medicine. 2nd ed. Philadelphia: W.B Saunders; 2000. P. 359-61.

10. Fellin F, Murphy S. Hematologic problem in the preoperative patient. Med Clin N Am. 1987; 71: 477-87.

11. Israels S, Schwetz N, Boyar R, McNicol A. Bleeding disorders: characterization, dental considerations and management. J Can Dent Assoc. 2006; 72: 827. 